\title{
Drawing on theoretical knowledge to build evaluation capacity
}

\section{Lisa Dyson}

Many organisations engage in self-evaluation. This requires organisational capacity to undertake evaluation and then capacity to make use of evaluation findings. Organisations lacking sufficient capacity often engage in evaluation capacity building (ECB). Most ECB literature describes how professional external evaluators build organisational evaluation capacity. In contrast, this study explored how people who are not professional evaluators are building evaluation capacity within their own organisations. This study identified four high schools in two geographic areas that are effective at the ongoing self-evaluation processes expected of all New Zealand schools. In-depth interviews were conducted with 13 educators at these secondary schools and the resulting data were analysed inductively. The findings highlighted that educators appeared to draw on learning theory to build organisational evaluation capacity. In contrast with many other ECB efforts in education, these schools emphasised building capacity for sense making and data interpretation. They built capacity by using collaboration, modelling, and the development and use of tools, all important concepts in sociocultural learning theory. This article contributes to the conversation 
around ECB by recommending greater attention be paid to the role of learning theories, specifically sociocultural theory. Although other organisational contexts will vary, the lessons learnt from these schools illuminate potential strategies for any organisation seeking to increase its capacity to conduct and use programme evaluations in its everyday activities.

Many organisations now carry out self-evaluation, which requires the capacity to do and use evaluation. Organisations lacking sufficient capacity often engage in evaluation capacity building (ECB) to increase their ability to conduct and use evaluation (Stockdill, Baizerman, \& Compton, 2002). Nearly all ECB literature describes how professional external evaluators build capacity in specific organisations or systems. In contrast, this article explores how people who are not professional evaluators are building evaluation capacity in their own organisations. It did so by studying selected secondary schools in New Zealand, which are expected to carry out ongoing self-review processes. Previous literature shows that New Zealand schools' evaluation capacity is highly variable with few schools having strong processes in place, possibly because of insufficient systemic ECB (Timperley, 2013). This study aimed to contribute to the conversation around internally actioned organisational ECB by identifying secondary schools that are effective at self-evaluation and exploring how they build capacity. After a brief look at the literature on evaluation capacity, ECB, and the context of school self-evaluation in New Zealand, this introduction turns to an explanation of sociocultural learning theory. This learning theory was a lens for understanding how New Zealand secondary school teachers build evaluative capacity. 


\section{School self-evaluation in New Zealand}

Since New Zealand schools are self-managing, the system depends on school self-evaluation. Self-evaluation is evaluation that is initiated and conducted by the school itself to assess its functioning and support its decision making, learning, and school improvement (Schildkamp \& Vissher, 2010). The scope of this activity can vary from individual teacher reflective practice through to school-wide analysis of data to inform planning and resource allocation (Mutch, 2012). Each New Zealand school is expected to carry out an ongoing process of evaluation for improvement but can select the approach as well as the tools used (Education Review Office, 2015). An Organisation for Economic Cooperation and Development (OECD) report has noted that, in New Zealand, "school self-review is at the heart of quality assurance and improvement processes. The basic premise is that schools are best placed to analyse their own contexts" (Nusche, Laveault, MacBeath, \& Santiago, 2012, p. 89).

\section{Evaluation capacity}

In New Zealand schools, as in any type of organisation, conducting self-evaluation requires evaluation capacity. Evaluation capacity is the competencies and structures necessary to carry out evaluation and the ability to use evaluation findings in decision-making processes (Bourgeois, Whynot, \& Thériault, 2015)which can be thought of as the competencies and structures required to conduct high-quality evaluation studies (capacity to do. Evaluation capacity encompasses the evaluation knowledge, skills, and attitudes of individual people. These include the ability to develop evaluative questions, use logic models, conduct surveys and interviews, analyse data, as well as having a favourable attitude towards evaluation (Huffman, Thomas, \& Lawrenz, 2008). Evaluation capacity also emphasises the organisational-level processes necessary to create and 
sustain quality evaluation. These can include strategic planning, continuous improvement strategies, professional development policies, and positive attitudes towards evaluation (Stockdill et al., 2002).

Evaluation capacity in the context of school self-evaluation is an issue in many countries around the world. Most economically advanced countries now prioritise school self-evaluation, but school personnel often lack sufficient evaluation capacity to carry it out effectively (MacBeath, 2006; McNamara \& O’Hara, 2008; Vanhoof \& Van Petegem, 2013). Self-evaluation processes "demand knowledge and skills from schools which cannot be simply pulled out of a hat ... It is no easy matter for schools to initiate and implement a systematic and cyclical process of self-evaluation" (Vanhoof \& Van Petegem, 2013, p. 275). Even if they can obtain self-evaluation data, many schools then find it difficult to use this information to make school improvements (Schildkamp \& Vissher, 2010). Several reasons account for this difficulty, including time constraints and teachers' lack of knowledge in adapting their instructional strategies (Datnow, Park, \& Kennedy-Lewis, 2012).

\section{Evaluation capacity building}

Support for organisations to develop evaluation capacity can occur through ECB, the intentional work to increase the ability of an organisation to conduct and use evaluation (Stockdill et al., 2002). "The ultimate goal of ECB is sustainable evaluation practice-where members continuously ask questions that matter, collect, analyze, and interpret data, and use evaluation findings for decision-making and action" (Preskill \& Boyle, 2008, p. 444). Building evaluation capacity is not merely skill-building, it also involves building evaluation practice and incorporating evaluation into the life of an organisation. ECB tries to create a system where the use of evaluation is standard practice, or the ordinary "way we do things around here" (Stockdill et al., 2002, p. 9). 
The ECB discussed in literature is nearly always an intervention by a professional evaluator to enhance the capacity of an organisation to do and use evaluation. ECB generally involves an evaluator providing training, technical assistance, written materials, consultation, coaching/mentoring, or immersion approaches to one or more staff within an organisation or system (Huffman et al., 2008; Preskill \& Boyle, 2008).

\section{New Zealand school evaluation capacity and ECB}

As in many other countries, the evaluation capacity of New Zealand schools is highly variable and only a minority of schools have strong evaluation processes in place (Mutch, 2012; Nusche et al., 2012; Timperley, 2013). A Ministry of Education initiative found that evaluative capacity was crucial to, but lacking in, school self-review processes (Timperley, 2013). Similarly, in a school improvement initiative, the majority of schools, even with support, did not have robust enough data to build a self-review process (Lai, 2013). A recent Education Review Office (ERO) national report indicated that secondary schools are not universally using effective self-evaluation processes (ERO, 2014). Only one-quarter of schools in the sample were judged to be effectively inquiring into their annual National Certificate of Educational Achievement (NCEA) achievement data and then developing activities, innovations, or approaches to improve achievement. Since schools are self-managing, the "success of the system is very dependent on the capacity of individuals in a variety of settings with differing skills, knowledge, and ability levels" (Ryan \& Timmer, 2013, p. 201).

Several scholars, such as Timperley (2013), cite the insufficient investment in systemic ECB in the New Zealand education sector. Lai (2013) agreed that the responsibility for school self-evaluation is given to "individual schools with little guidance from central government on 
how to do so" (p. 68). An OECD review of the New Zealand schooling evaluation system recommended improving support structures to promote school self-evaluation (Nusche et al., 2012).

\section{Drawing on learning theory}

Because evaluation capacity is variable in New Zealand schools and has lacked major, systemic ECB, this study aimed to identify secondary schools that are effective at self-evaluation and explore how they build capacity for these processes. As will be discussed in the Results section, the findings showed that these secondary schools appear to be drawing on concepts of sociocultural learning theory to build evaluation capacity. The study did not set out to use this approach, but analysis of the data suggested that this theory reflected what was happening in schools and could be a helpful framework for understanding ECB. To begin to understand how the schools in this study drew from sociocultural learning theory and what this theory can bring to ECB practice, a brief overview of this theoretical tradition is helpful. It is proposed that ECB pay greater attention to learning theories and, more specifically, sociocultural theory. Currently, the literature on ECB is largely atheoretical (Huffman et al., 2008). The related literature on interventions to increase teachers' use of data also lacks theory (Marsh \& Farrell, 2014).

Before expanding this argument, it is necessary to explain what is meant by "theory" here, since the field of evaluation understands the concept of theory in "fragmented" and "often confusing" ways (Leeuw \& Donaldson, 2015, p. 478). Evaluators draw on "evaluation theories" (i.e., theories of practice for conducting evaluations); for example, empowerment evaluation, or participatory evaluation. Another widespread use of "theory" in evaluation is a theory of change approach describing processes of change in an initiative by outlining linkages between the intervention and expected outcomes. 
These programme theories might be called small-t theories (Leeuw \& Donaldson, 2015). These are contrasted with capital $T$ theories, sometimes called explanatory, substantive, or scientific theories. Leeuw and Donaldson (2015, p. 472) argue that evaluation should draw on more capital $\mathrm{T}$ theories that are "tested and robust explanatory theories from the (social, behavioral and policy) sciences". Schwandt (2014) echoes this, suggesting that drawing on theoretical knowledge can help with dilemmas of practice. Similarly, this article argues that the field of evaluation could benefit from attending to and drawing on explanatory theories.

One category of theories for the field of evaluation and particularly ECB to potentially draw on are learning theories. These include behaviourism, cognitivism, metacognitivism, social constructivism, and sociocultural theories. For example, in the behaviourist model, learning is an individual activity, learners are fairly passive participants in the learning process, and knowledge is generally seen as transferable from context to context (Svinicki, 1999). The desired behaviours are divided into small, carefully sequenced steps, with each step taught to mastery before going on to higher level steps. Although they do not use the label of "behaviourist", Huffman and colleagues (2008) contend that ECB is often conceived of as a linear, step-by-step process, which is similar to a behaviourist approach.

\section{Sociocultural theory}

The sociocultural approach to learning sits in contrast with this approach. Originally based on the writings of Vygotsky (1978), a variety of sociocultural theories of learning have been proposed (e.g., Brown, Collins, \& Duguid, 1989; Lave \& Wenger, 1991). Learning is not conceived as an isolated process of an individual's acquisition of information, but as a process of meaning-making and knowledge construction that occurs through social interactions and activity. 
Sociocultural learning theory argues that learning is inherently a social phenomenon that occurs through dialogue and reflection with colleagues (Lave, 1996; Vygotsky, 1978; Wenger, 1998). Through dialogue, practitioners can challenge each other's beliefs and interpretations, which "can lead to new shared understandings and deeper engagement in particular activities than would otherwise be possible by individuals operating alone" (Honig \& Ikemoto, 2008). The sociocultural lens also emphasises the importance of the particular context where learning occurs and the learner's connection with, and involvement in, this environment.

Within this social learning, various "scaffolds" or supports help learners to deepen their engagement in particular learning processes (Vygotsky, 1978). These scaffolds support the learner's understanding and independent performance. One such support is assistance from an experienced teacher or "more knowledgeable other" (Vygotsky, 1978). A practice the teacher might use is modelling particular activities by demonstrating the practice and explaining their underlying thought process to bring "thinking to the surface" and make it "visible" (Brown et al., 1989, p. 33). Honig and Ikemoto (2008) claim that it is "particularly powerful" to engage "others in dialogue about the purposes and nature of the practices-so others know not just what participation in these practices entails but why they should participate in particular ways" (p. 333).

Another scaffold is the use of tools to help deepen individuals' engagement in particular practices. According to sociocultural learning theory, tools are the manifestation of new ideas (Marsh \& Farrell, 2014; Wenger, 1998). Tools may be physical, such as a shovel, but tools can also be psychological; much as physical tools can support physical activities, psychological tools can support human learning (Vygotsky, 1978). Grossman, Smagorinsky, and Valencia (1999) delineate two kinds of tools: conceptual and practical. Conceptual 
tools are principles, theories, frameworks, and ideas designed to frame how people think about certain issues; people use conceptual tools as heuristics to guide their decision making and practice (Grossman et al., 1999). Practical tools are more concrete practices, resources, and strategies. Tools help communicate messages about what individuals in a workplace should and should not do; however, the meaning of these tools is not set in stone, but is negotiated within a community (Brown et al., 1989).

Sociocultural theories also emphasise the concept of learning as participation in practice, not separate from practice. Schwandt (2005) points out that many capacity-building workshops, seminars, and courses conceive of learning as separate from everyday practices of doing: "we readily assume that 'learning' is some activity that takes place on a special occasion when a practitioner is not busy 'doing'" (p. 328). However, in sociocultural learning theory, learning and application are not separate processes.

In education, sociocultural learning theories are used to make sense of student learning and teaching, and several scholars have used these theories to understand school improvement efforts (Gallucci, Van Lare, Yoon, \& Boatright, 2010; Honig \& Ikemoto, 2008; Ikemoto \& Honig, 2010; Marsh \& Farrell, 2014). This study draws on sociocultural learning theory as a lens for understanding how New Zealand secondary school teachers build evaluative capacity.

\section{Methods}

\section{Participants and settings}

This study was part of larger research on school self-evaluation in New Zealand secondary schools. This study tried to identify selected secondary schools that are effective at self-evaluation and explore how they build capacity within their organisation. Four secondary 
schools were purposefully selected based on three criteria: they had previously been identified by ERO as successful at self-evaluation; they were mid-decile schools (deciles 4-8); and they had student achievement levels that were above average for their decile level. To identify schools, the ERO reports of all 37 mid-decile schools in two geographic areas of the North Island were read along with other school documents, school websites, and independent publications on school achievement levels. Schools with similar decile ranges were chosen because they have similar levels of funding available to them for self-review and capacity building. Within these selection criteria, diversity was sought among the schools in terms of size, location, single-sex/co-ed, state/integrated, and length of tenure of the principal.

The four schools were each given a pseudonym based on a New Zealand native tree, and are described briefly below:

- Totara School is a very large, co-ed state school with a very diverse student body and an established principal. It has high University Entrance results for both boys and girls for its decile level.

- Kauri School is a large, co-ed, integrated (Catholic) school, with a less-diverse student population that is approximately two-thirds European. It has high NCEA Level 2 achievement rates, a fairly new principal, and new deputy principal.

- Matai School is a very large, co-ed state school with a diverse study body, a sizeable Māori population, and a fairly new principal. Māori and Pacific student achievement is above the national average.

- Rata School is a medium-sized, single-sex state school with a large Māori population and an established principal. Māori student achievement at Rata is significantly higher for NCEA at all levels compared to Māori students nationally. 


\section{Data collection}

The primary data collection method for this study was in-depth semistructured interviews with 13 people. Within each school, three people were usually interviewed: a principal or deputy principal, and two staff who were not part of the school's senior leadership team. At the first school, an additional head of faculty was interviewed. Many of those interviewed were heads of faculty or department, and all were knowledgeable about their school's self-evaluation processes. Interviews lasted approximately 1 hour, ranging from 58 minutes to 79 minutes. (See below, Data analysis, for information about interview questions.) Documents from each school were also analysed to gain a more complete understanding of the schools' processes. These included ERO reports, background information on the schools, and tools used by the schools to build capacity, such as templates and handbooks.

\section{Data analysis}

Data analysis began with transcribing the audio recordings of the interviews and reading them to become familiar with the data. For this study, segments of interview data relating to ECB were pulled out from the wider interview data. These were primarily participants' responses to the interview questions: "How have teachers and school leaders in this school acquired the capacity to be able to carry out these (school self-evaluation) processes?" "What resources have you drawn on to build capacity?" Any other instances in the interviews where participants discussed the concept of capacity building were also sought.

I began by writing detailed descriptions of each school's capacity-building efforts, with an emphasis on how they differed. After further data analysis and in-depth discussions with two colleagues, I noticed commonalities between the cases and therefore decided that a thematic analysis was more appropriate (Miles, Huberman, 
\& Saldaña, 2014). I then reread the data, assigned codes to segments of data, and grouped together similar data into themes. After several rounds of data analysis, I identified that educators were describing using processes consistent with sociocultural learning theory and that this framework could help to understand the way schools were building evaluative capacity. When I noticed the pattern of the prevalence of these practices, I developed codes for these and searched for additional examples among the interview data.

\section{Results and discussion}

\section{Lacking capacity}

Participants suggested that some teachers in their schools lacked capacity in evaluation activities. They indicated that some evaluation tasks are new for teachers, who may find them difficult. Often there is an assumption that teachers are all capable of doing these tasks. A participant explained that this includes believing that teachers can effectively interpret their data:

There's an assumption that everyone knows their data or has an ability to interpret it, because $I$ can look at my data and say 'high', 'low', 'issue'. I can do that, so I think we make an assumption that all teachers can do that. (Totara, deputy principal)

Some admitted that, in the past, perhaps they had not focused on capacity building to the extent that was needed. The same deputy principal said, "You've got to teach people to evaluate effectively. I think maybe we've been guilty of just saying go on, review. And I think you have to teach people how to review." The remainder of this section explores what and how the schools taught teachers to evaluate effectively. Before discussing how schools attempted to build capacity, it is valuable to understand what skills and traits were the focus of ECB efforts. 


\section{Sense making}

Schools in this study emphasised building capacity for sense making rather than narrow technical skills. These schools did not focus their capacity building on increasing teachers' technical data collection and analysis skills such as building and accessing student data systems, producing graphs, or making statistical calculations like determining effect size. Instead, the schools focused on learning how to engage in meaningful inquiry, particularly collaborative inquiry. The schools all had effective data management systems for tracking and monitoring student achievement but believed that capacity building was still important; they saw the monitoring systems as necessary but not sufficient for effective self-evaluation. They focused on building capacity for using the available data to improve school practices through asking questions, interpreting information, solving problems, and developing action plans based on the data. Participants explained that they believed the interpretation of data was more important than technical data skills:

I don't think individual teachers necessarily need to have a lot more work on tracking the data ... The important part is the interpretation that comes through in discussion within departments. That is where you can say we notice this year we had lower success in that [NCEA] standard than the other, why is that? (Matai, teacher)

We want the domain of the teacher to be on reflection, not around the skills required for analysis of data. [We say to teachers] 'Okay, we're going to ask you to do unit review but we're not going to ask you to have to do all the calculations, we just want you to worry about the reflection.' (Rata, deputy principal)

This emphasis on reflection, interpretation, and improvement rather than on discrete technical skills is reflected in the concept of evaluative thinking. This kind of evaluative thinking requires sense 
making, setting priorities, asking questions that matter, translating findings into instructional practice, and ensuring equity. Evaluative capacity is not about the data in itself, "but about the quality of the knowledge that emerges from this process. As we see it, good knowledge is founded on asking good questions, having good data, and engaging in good thinking" (Earl \& Seashore Louis, 2013, p. 199).

The schools' focus on interpretation, evaluative thinking, and improvement sits in contrast with much of the literature on capacity building for data use in schools that focuses on the more technical skills required to carry out evaluation. In a programme to support New Zealand schools, Gan, Irving, and McKinley (2014) have focused their capacity-building efforts on enabling schools to develop and maintain databases and data management systems. A recent survey in the US found that, although most districts are providing schools with support on how to access student data from data systems, they are far less likely to provide educators with training on how to use the system to analyse student achievement or use the results to change their instructional practice (Means, Padilla, \& Gallagher, 2010). Much of the professional development about data use in education focuses on teaching data literacy skills in isolation rather than on how to use data to potentially change practice (Wayman $\&$ Jimerson, 2014). The schools in this study appeared to understand the importance of building capacity in the often-neglected skills of using self-evaluation data to make school improvements.

\section{How capacity was built}

The previous section discussed what schools focused on in their ECB and we will now turn our attention to how they built capacity. Previous studies using sociocultural learning theory to understand school improvement efforts identified several practices that were important in the current study: collaborative work, modelling, and 
the use of tools (Gallucci et al., 2010; Honig \& Ikemoto, 2008; Ikemoto \& Honig, 2010; Marsh \& Farrell, 2014).

\section{Collaboration}

For the schools in this study, ECB was collaborative and occurred through social interactions. Collaborative inquiry involves forming groups of educators who can work together as they use data to examine and improve their own practice or overall school functioning. Teachers in these schools engaged in many formal and informal social processes to build evaluative capacity. Even when teachers were conducting individual inquiries into their own practice, this was supported by collaborative groups. Teachers' individual inquiries were also linked to whole-school evaluation and development through capacity building. The group structures took different forms, but the most frequent were evaluative discussions in departments (called "co-construction meetings" in one school) or cross-curricular professional development in Professional Learning Groups (PLGs). A head of faculty described that these cross-curricular groups were not ad hoc, but required planning:

We also thought quite a lot about collaboration and how to put people together and who might be a critical friend to somebody ... We all came together across faculties in a group of say 10 or 15 and we talked about a [capacity building] reading for instance, and we pooled our ideas and reflections. (Totara, head of faculty)

The purpose of the groups was to conduct self-evaluation collaboratively, support educators in conducting inquiry into practice, and make this inquiry productive (Wayman \& Jimerson, 2014).

This emphasis on collaboration is different from the way teachers often work in isolation (Little, 1990), but is strongly supported by the sociocultural learning theory understanding of learning as an inherently social phenomenon that occurs through dialogue and 
reflection with colleagues (Lave, 1996; Vygotsky, 1978; Wenger, 1998). Schwandt (2017) explained this social learning process:

In dialogues, people exchange experiences and perspectives, and this helps them to gain a better, fuller understanding of the situation ... $[D]$ ialogue across these perspectives ... is understood as an ongoing, social learning process in which participants develop new and richer understandings of their practice. (p. 15)

The concept of educators learning through social interactions is reflected in a trend in the wider teacher professional development literature towards the social in adult learning (Timperley, Wilson, Barrar, \& Fung, 2007) since research suggests that educators learn well collaboratively (Wayman \& Jimerson, 2014). These observations are not limited to educators, however, and the importance of learning through social interactions may be valuable to the practice of ECB in any sector.

\section{Modelling}

A specific collaborative practice that was used by the schools to increase skills and improve attitudes was modelling. This was usually used when teachers or school leaders shared their experiences of conducting an inquiry into their own practice. In PLGs, teachers shared their experiences, and articulated their thinking and the decision making behind their actions. Then they reflected on what had occurred in the classroom as a result of experimenting with different practice. At Totara School, modelling had become a formalised, ongoing process in which each school term, eight or nine teachers were chosen to publicly share their inquiries:

We are picking high quality inquiries to present and try to model that and say to people look, here is what we think is good practice ... The teacher will talk about how it went or what has occurred and what was learned. And that has proved to be pretty powerful. (Totara, head of faculty) 
Teachers modelling effective inquiries and reflecting on what they had learnt as a result brought their "thinking to the surface" and made it "visible" (Brown et al., 1989) so others could learn from it. A deputy principal explained that this process was effective even if teachers did not share the same content area (e.g., maths, history, physical education). Teachers could learn from others' experiences and apply it to their own content area. By modelling the underlying skills of self-evaluation, leaders attempted to increase understanding and capabilities to facilitate teachers doing this work independently in the future.

Although scholars emphasise the cognitive and metacognitive skills learnt from modelling (Lave, 1988; Marsh \& Farrell, 2014), the teachers in this study seemed to also consider the affective aspects and to view modelling as a nonthreatening way to increase positive attitudes towards self-evaluation. A participant described how she modelled her own inquiry for a resistant colleague:

Previously he had been very resistant. And I'm just quietly showing him my teaching as inquiry, being very careful. I'm just showing him what I'm doing and the video I've taken of students for my inquiry. And I say 'this is going to be my scanning, this is going to be my bringing in data' ... We're starting to see some progress. It helps with buy-in. And ever so slightly it's shifting. (Kauri, head of faculty)

In this quote, the teacher makes explicit her own processes and does so quietly and carefully, implying that it is important to be gentle and nonthreatening in order to overcome her colleague's resistance. Modelling also assisted with alleviating evaluation anxiety through school leaders showing vulnerability. Participants explained that listening to how colleagues described their self-reflection was "empowering" to others and made them more open to discussing their own practice. At Totara School, a participant suggested that 
leaders showing their own vulnerability when modelling was valuable for building capacity among the staff:

The deputy principals have been good at standing up and showing lots of failures around inquiry and [a deputy principal] last year got up and really exposed things that hadn't worked well in her class. The inquiry had helped, but it was mixed. That was good to see examples of self-reflection and review that hadn't necessarily worked. So you are putting yourself in quite vulnerable situations. (Totara, head of faculty)

Taut, 2007 argued that leaders' modelling of learning from self-evaluation set the tone in an organisation and highlighted that learning from evaluation is valued.

Educators at the schools explained that having systems and processes in place and specific time set aside were crucial in embedding self-evaluation in the school. A Kauri teacher explained: "So I think the fact that the school very systematically has invested in the model and in coaching and in giving people time to do it has probably helped to shift everybody."

Professional evaluators in any field whose work includes ECB can learn from the practice of using modelling in ECB work. To create an organisational climate favourable to evaluation, ECB professionals and organisational leaders can model what effective evaluation use looks like (Preskill \& Torres, 1999). This allows others to more fully understand the power of evaluation use and helps to build a shared commitment to evaluation. ECB professionals can also, for example, make explicit their thought processes while analysing data as an effective strategy for building evaluation skills.

\section{Tools}

The practices above were assisted by the use of various tools. As mentioned previously, according to sociocultural learning theory, tools 
can be conceptual or practical. An example of a conceptual tool from a school in this study was a framework for thinking about self-evaluation called the Spiral of Inquiry (Timperley, Kaser, \& Halbert, 2014). A deputy principal explained that this conceptual tool had guided their thinking around self-evaluation: "I think it's become a bit of a model for us, a framework, not only for teachers unpacking what's going on in their classroom but for us unpacking what we are doing as a school."

The practical tools used by the schools in this study were developed internally and varied depending on the particular emphasis of the school. For example, Matai School attempted to raise the profile of using data by using the tool of visual displays around the school containing data on student achievement and attendance. The principal explained the symbolic importance: "[I]t's a signal that this is important." Totara School had developed an inquiry handbook that was given to teachers at the beginning of the year and contained readings, the programme of work, the inquiry model, and a profile of effective teaching developed by the school. The school's effective teaching profile was actually a conceptual tool, conveying statements about the practices that they believed promoted effective instruction. Rata School had a digital template to make ongoing self-evaluation of each NCEA unit easier for teachers. The template contained boxes asking teachers what went well, what did not go well, how they knew this, and what needed to change. Teachers were asked to answer these questions using three pieces of data: student feedback; student achievement; and their own reflections. The information on this template was used to guide collaborative discussions in their departments. A participant explained that the tools were a way to build teachers' capacity and help them be more evaluative:

We ask everyone to complete [the document] but by asking them to complete it, we are providing scaffolding at the same time. We're 
not asking them to produce graphs because it's done automatically. So trying to take away some of the barriers to doing a process like this by providing the template and the scaffold that goes with it ... It's helping the teachers be more reflective, it's helping them in their learning areas develop better processes for reviewing their units of work and the like. (Rata, deputy principal)

Tools reflect the principles and ideas of school leaders and shape the attention, thinking, and behaviour of members of the organisation. As a participant in research by Honig and Ikemoto (2008) stated, "The tool has to carry the theory as well as the action ... We had to build the tools that produced the action rather than tell people to have the action" (p. 349). In this study, Rata School's template tool carries several theories: analysis and interpretation is more important than calculating statistics and producing graphs; teachers' self-reflection is important, as is student voice; data should be interpreted collectively. In sociocultural theory, tools reflect the theory but also "tools shape our consciousness" (Lofthouse \& Leat, 2013, p. 11). Kallemeyn (2014) suggested that processes and protocols for capacity building in self-evaluation are meaningful because they convey to teachers the types of data that they should notice, and how they should discuss and interpret these data, and then discuss their implications for practice and plan for improvement.

The staff in these schools emphasised that these processes and tools need to be organised and ongoing, rather than ad hoc, in order to be effective. A participant explained:

I keep on coming back to that systematic thing, that does seem to be important ... It clearly doesn't rely on me or anyone else, it just happens [in our school now] ... Schools are complicated organisations, you know, so the idea that this will just happen is just too much of a romantic kind of hope. (Totara, head of faculty) 
The importance of ongoing use of tools and processes for ECB has been echoed in the literature. Preskill and Torres (1999) argue that building sustainable evaluation practice in organisations requires implementing systems, processes, policies, and plans to help embed evaluation into the way the organisation works. King (2016) argues that building these structures and processes helps to minimise organisations losing capacity because of staff turnover. In a school improvement effort, Ikemoto and Honig (2010) found that the tools developed and used during a capacity-building initiative enabled teachers to engage with research-based ideas in ways that shaped their thinking and actions. This was particularly true when the tools: were modelled; included knowledge from both research and practice; were linked to practitioners' local situations; and were adapted over time.

\section{Conclusion}

This study argues that the use of learning theory and specifically, sociocultural theory, contributes to the scholarly conversation about ECB. The way educators in this study conducted ECB provides a model for how organisations might increase their capacity to conduct and use evaluation in their everyday activities.

One way that sociocultural theory contributes to the conversation about ECB is by drawing attention to the learning process. Through a sociocultural lens, learning is not conceived of as merely the acquisition of a set of skills and a body of knowledge, but instead as a process in which individuals engage with other people and various tools to make sense of information and construct new knowledge (Vygotsky, 1978). It also emphasises the particular context where learning occurs and the fact that the learner is connected with, and involved in, this learning context. In this way, sociocultural theory is helpful for considering the relationship between individual practitioner learning and organisational support for ECB. Given 
the limitations of examining only four schools, the current study is best understood as exploratory. However, it does raise the possibility that both ECB facilitators and organisational leaders might consider drawing on learning theories when designing their efforts to encourage self-evaluation. Even a limited understanding of these theories could impact our ECB efforts because this enables us to design activities that incorporate our understanding of how people learn.

When designing activities and processes, both ECB facilitators and organisational leaders might want to consider if their efforts reflect the practices that sociocultural learning theory suggests are most effective for learning. For example, an organisation could support sense making in a variety of ways, such as allowing practitioners to have time and space for collaboration. They might also want to consider the tools that support the learning process and how these tools prompt users to engage in new ways of thinking and reflection. ECB facilitators might also assist with tool use by modelling how to use a tool or engage in new work practices. Modelling can be particularly valuable when modellers use metacognitive strategies that make their thinking visible so that practitioners understand not just what to do but why. Modelling can help practitioners determine how they could apply new practices and tools in their day-to-day work.

This article also contributes to the largely atheoretical body of research on ECB. Even if they do not employ strategies from sociocultural theory, evaluators may want to pay greater attention to the concepts implied in the way they conduct ECB. It can be valuable to unpack the assumptions underlying their capacity-building activities and to make them more explicit. Much as evaluators often ask programme stakeholders to unearth the tacit theories underlying their programme activities, it might be beneficial to pay greater attention to the theories underlying the way we do ECB. 


\section{Acknowledgements}

The author wishes to thank Carol Mutch, Ritesh Shah, two anonymous reviewers, and the Editor of Evaluation Matters for their insightful comments on earlier drafts of this article. I would also like to thank the educators who gave generously of their time to participate in this study.

\section{References}

Bourgeois, I., Whynot, J., \& Thériault, É. (2015). Application of an organizational evaluation capacity self-assessment instrument to different organizations: Similarities and lessons learned. Evaluation and Program Planning, 50, 47-55. http://doi.org/10.1016/j.evalprogplan.2015.01.004

Brown, J. S., Collins, A., \& Duguid, P. (1989). Situated cognition and the culture of learning. Educational Researcher, 18(1), 32-42.

Datnow, A., Park, V., \& Kennedy-Lewis, B. (2012). High school teachers' use of data to inform instruction. Journal of Education for Students Placed at Risk, 17(4), 247-265. http://doi.org/10.1080/10824669.2012.718944

Earl, L., \& Seashore Louis, K. (2013). Data use: Where to from here? In K. Schildkamp, M. Lai, \& L. Earl (Eds.), Data-based decision making in education: Challenges and opportunities. (pp. 193-204). Dordrecht, The Netherlands: Springer Publishing.

Education Review Office (ERO). (2014). Raising achievement in secondary schools. Wellington: Author.

Education Review Office (ERO). (2015). Internal evaluation: Good practice. Wellington: Author. Retrieved from http://www.ero.govt.nz/publications/ internal-evaluation-good-practice/

Gallucci, C., Van Lare, M. D., Yoon, I. H., \& Boatright, B. (2010). Instructional coaching: Building theory about the role and organizational support for professional learning. American Educational Research Journal, 47(4), 919-963. http://doi.org/10.3102/0002831210371497 
Gan, M., Irving, S. E., \& McKinley, E. (2014). Early warning systems in schools: Tracking and monitoring students' progress using NCEA achievement data. Set: Research Information for Teachers, 2, 54-60.

Grossman, P. L., Smagorinsky, P., \& Valencia, S. (1999). Appropriating tools for teaching English: A theoretical framework for research on learning to teach. American Journal of Education, 108(1), 1-29.

Honig, M. I., \& Ikemoto, G. S. (2008). Adaptive assistance for learning improvement efforts: The case of the Institute for Learning. Peabody Journal of Education, 83(3), 328-363. http://doi. org/10.1080/01619560802222327

Huffman, D., Thomas, K., \& Lawrenz, F. (2008). A collaborative immersion approach to evaluation capacity building. American Journal of Evaluation, 29(3), 358-368. http://doi.org/10.1177/1098214008318798

Ikemoto, G. S., \& Honig, M. I. (2010). Tools to deepen practitioners' engagement with research: The case of the institute for learning. In M. K. Stein \& C. E. Coburn (Eds.), Research and practice in education: Building alliances, bridging the divide (pp. 93-107). Lanham, MD: Rowman \& Littlefield Publishers.

Kallemeyn, L. M. (2014). School-level organizational routines for learning: Supporting data use. Journal of Educational Administration, 52(4), 529-548. http://doi.org/10.1108/JEA-02-2013-0025

King, J. A. (2016). Evaluation capacity building through the years [webinar]. American Evaluation Association.

Lai, M. (2013). A thousand flowers blooming: The implications of school self-review for policy developers. In M. Lai \& S. Kushner (Eds.), $A$ developmental and negotiated approach to school self-evaluation (pp. 57-72). Bingley, UK: Emerald Group Publishing.

Lave, J. (1988). Cognition in practice. Cambridge, U.K: Cambridge University Press. 
Lave J. (1996). The practice of learning. In S. Chaiklin \& J. Lave (Eds.), Understanding practice: Perspectives on activity and context, (pp. 3-34). Cambridge: Cambridge University Press.

Lave, J., \& Wenger, E. (1991). Situated learning: Legitimate peripheral participation. New York: Cambridge University Press.

Leeuw, F. L., \& Donaldson, S. I. (2015). Theory in evaluation: Reducing confusion and encouraging debate. Evaluation, 21(4), 467-480. http://doi. org/10.1177/1356389015607712

Little, J. W. (1990). The persistence of privacy: Autonomy and initiative in teachers' professional relations. Teachers College Record, 91(4), 509-536.

Lofthouse, R., \& Leat, D. (2013). An activity theory perspective on peer coaching. The International Journal of Mentoring and Coaching in Education, 2(1), 8-20. http://doi.org/10.1108/20466851211231585

MacBeath, J. (2006). School inspection and self-evaluation: Working with the new relationship. London: Routledge.

Marsh, J. A., \& Farrell, C. C. (2014). How leaders can support teachers with data-driven decision making. Educational Management Administration \& Leadership, 43(2), 1-21. http://doi.org/10.1177/1741143214537229

McNamara, G., \& O'Hara, J. (2008). Trusting schools and teachers: Developing educational professionalism through self-evaluation. New York, NY: Peter Lang.

Means, B., Padilla, C., \& Gallagher, L. (2010). Use of education data at the local level: From accountability to instructional improvement. Washington, DC: US Department of Education Office of Planning, Evaluation and Policy Development.

Miles, M. B., Huberman, A. M., \& Saldaña, J. (2014). Qualitative data analysis: A method sourcebook (3rd ed.). Thousand Oaks, CA: Sage.

Mutch, C. (2012). Complementary evaluation: The development of a conceptual framework to integrate external and internal evaluation in the New Zealand school context. Policy Futures in Education, 10(5), 569-586. http://doi.org/10.2304/pfie.2012.10.5.569 
Nusche, D., Laveault, D., MacBeath, J., \& Santiago, P. (2012). OECD reviews of evaluation and assessment in education: New Zealand 2011. Paris: OECD. Retrieved from http://dx.doi.org/10.1787/9789264116917-en

Preskill, H., \& Boyle, S. (2008). A multidisciplinary model of evaluation capacity building. American Journal of Evaluation, 29(4), 443-459. https:// doi.org/10.1177/1098214008324182

Preskill, H., \& Torres, R. (1999). Evaluative inquiry for learning in organizations. Thousand Oaks, CA: Sage.

Ryan, K. E., \& Timmer, J. D. (2013). New Zealand style school review: A view from outside. In M. Lai \& S. Kushner (Eds.), A developmental and negotiated approach to school self-evaluation (pp. 195-206). Bingley, UK: Emerald Group Publishing.

Schildkamp, K., \& Vissher, W. (2010). The utilization of a school selfevaluation instrument. Educational Studies, 36(4), 371-390. http://doi.org/ doi.org/10.1080/03055690903424741

Schwandt, T. A. (2005). On modeling our understanding of the practice fields. Pedagogy, Culture \& Society, 13(3), 313-332. http://doi. org/10.1080/14681360500200231

Schwandt, T. A. (2014). On the mutually informing relationship between practice and theory in evaluation. American Journal of Evaluation, 35(2), 231-236. http://doi.org/10.1177/1098214013503703

Schwandt, T. A. (2017, April). The centrality of engagement and ethics to the task of evaluating for equity. In Educational Review Office Professional Forum, Auckland.

Stockdill, S. H., Baizerman, M., \& Compton, D. W. (2002). Toward a definition of the ECB process: A conversation with the ECB literature. New Directions for Evaluation, (93), 7-25.

Svinicki, M. D. (1999). New directions in learning and motivation. New Directions for Teaching and Learning, (80), 5-27. 
Taut, S. (2007). Studying self-evaluation capacity building in a large international development organization. American Journal of Evaluation, 28(1), 45-59. http://doi.org/10.1177/1098214006296430

Timperley, H., Kaser, L., \& Halbert, J. (2014). A framework for transforming learning in schools: Innovation and the spiral of inquiry. Centre for Strategic Education Seminar Series 234, Melbourne, Australia. Retrieved from https://educationcouncil.org.nz/sites/default/files/49.\%20Spiral\%20of\%20 Inquiry\%20Paper\%20-\%20Timperley\%20Kaser\%20Halbert.pdf

Timperley, H., Wilson, A., Barrar, H., \& Fung, I. (2007). Best evidence synthesis iterations (BES) on professional learning and development. Wellington: Ministry of Education.

Timperley, H. S. (2013). The New Zealand educational context: Evaluation and self-review in a self-managing system. In M. Lai \& S. Kushner (Eds.), A developmental and negotiated approach to school self-evaluation (Vol. 14, pp. 23-38). Bingley, UK: Emerald Group Publishing. http://doi. org/10.1108/S1474-7863(2013)0000014002

Vanhoof, J., \& Van Petegem, P. (2013). Judging and explaining the quality of school self-evaluations: Indicators and findings on meta-evaluation from a Flemish perspective. In M. Lai \& S. Kushner (Eds.), A developmental and negotiated approach to school self-evaluation (Vol. 14, pp. 275-291). Bingley, UK: Emerald Group Publishing.

Vygotsky, L. (1978). Mind in society: The development of higher psychological processes. Cambridge, MA: Harvard University Press.

Wayman, J. C., \& Jimerson, J. B. (2014). Teacher needs for data-related professional learning. Studies in Educational Evaluation, 42, 25-34.

Wenger, E. (1998). Communities of practice: Learning, meaning, and identity. Cambridge: Cambridge University Press.

\section{The author}

University of Auckland

Email: Lisa.dyson@auckland.ac.nz 